\title{
Welches Insulinregime bei Typ-2-Diabetes?
}

\author{
Reicht die orale antidiabetische \\ Therapie bei Typ-2-Diabetikern nicht \\ mehr aus, senken basale oder pran- \\ diale Insulinregimes das $\mathrm{HbA}_{1 \mathrm{c}}$ mehr \\ als die Zugabe biphasisch wirkender \\ Insuline.
}

- Hat man erst einmal ein erfolgreiches Studienmodell etabliert, lassen sich bei der Untersuchung von Patienten mit chronischen Krankheiten im Abstand von ein bis drei Jahren immer wieder neue und interessante Ergebnisse generieren, welche auch die Aufmerksamkeit von erstklassigen medizinischen Journalen finden.

Eine Studie dieser Art ist die sog. 4-T-Studie, deren 1-Jahres-Ergebnisse 2007 publiziert wurden und von der wir nun die 3-Jahres-Ergebnisse erfahren. Über 700 Patienten mit Typ-2Diabetes mit erhöhtem $\mathrm{HbA}_{1 \mathrm{c}}$-Werten unter maximalen Dosen von Metformin und Sulfonylharnstoffen wurden zusätzlich zu drei verschiedenen Insulinregimes randomisiert.

Gruppe 1 erhielt zweimal täglich ein biphasisch wirkendes Insulin (NovoMix $^{\circledR} 30$ ), Gruppe 2 dreimal täglich ein präprandial verabreichtes kurz wirksames Insulin (NovoRapid ${ }^{\circledR}$ ) und Gruppe 3 einmal täglich ein lang wirksames Basalinsulin (Levemir ${ }^{\circledR}$ ). Die Sulfonylharnstofftherapie wurde durch ein zweites Insulin ersetzt, wenn die Blutzuckerwerte inakzeptabel hoch blieben bzw. die $\mathrm{HbA}_{1 \mathrm{c}}$-Werte weiterhin über $6,5 \%$ lagen. Zielparameter waren die $\mathrm{HbA}_{1 \mathrm{c}}$-Werte, der Anteil von Patienten mit einem $\mathrm{HbA}_{1 \mathrm{c}}$ von $6,5 \%$ oder weniger, die Anzahl von Hypoglykämien und die Gewichtszunahme.

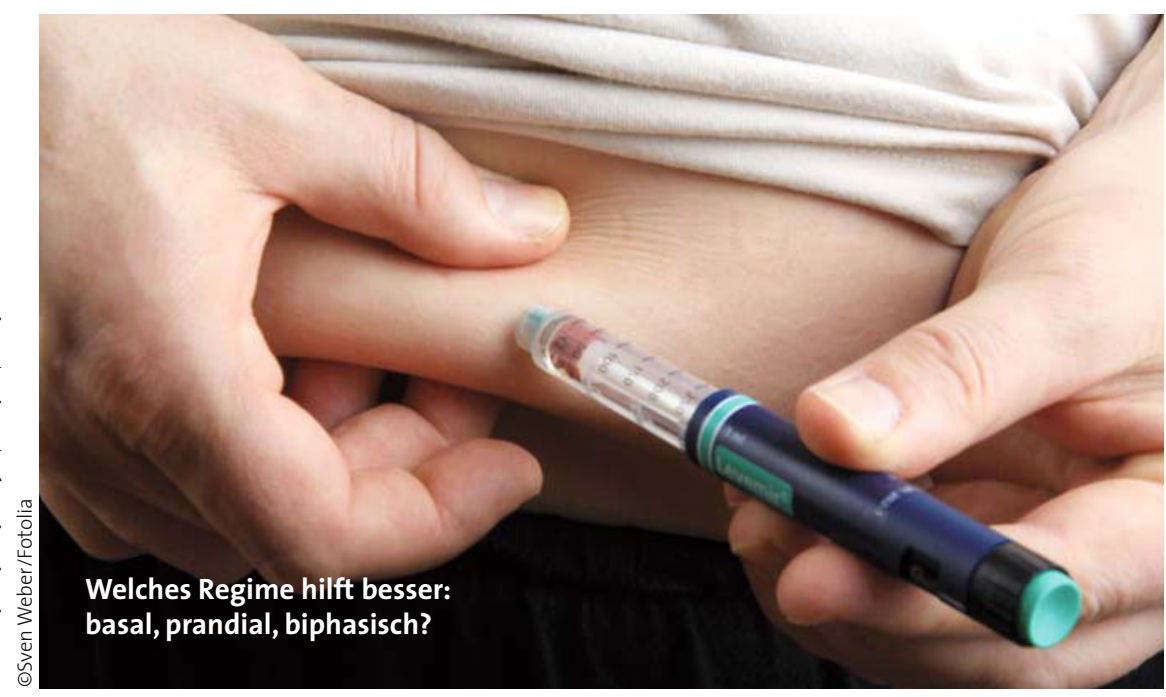

Nach dreijähriger Behandlungsdauer waren die medianen $\mathrm{HbA}_{1 \mathrm{c}}$-Werte in den drei Gruppen mit 7,1\% (biphasisch), 6,8\% (präprandial) und 6,9\% (basal) nicht signifikant verschieden. Der Anteil von Patienten mit einem $\mathrm{HbA}_{1 \mathrm{c}}$-Wert von 6,5\% oder weniger lag in der Gruppe des biphasischen Insulins dagegen nur bei 31,9\%, während in der prandialen Insulingruppe 44,7\% und in der basalen Gruppe 43,2\% diesen günstigen Wert erreichten.

Hinsichtlich der Hypoglykämien schnitt die basale Gruppe mit 1,7\% am besten $\mathrm{ab}$, während unter dem biphasisch wirkenden Insulin bei 3\% und in der Gruppe mit dem prandial verabreichten Insulin bei 5,7\% der Patienten derartige Ereignisse eintraten.

Die mediane Gewichtszunahme bewegte sich zwischen 3,6 $\pm 0,5$ und 6,4 $\pm 0,5 \mathrm{~kg}$ und war in der Gruppe mit der prandialen Insulingabe am ausgeprägtesten.

\section{Kommentar}

Die Studienergebnisse sprechen dafür, bei Versagen der oralen Therapie als Erstes ein basales Insulin hinzuzufügen. Bleibt die Einstellung ungenügend, wird die Therapie durch ein basales/prandiales Regime intensiviert. Allerdings sind die Unterschiede zwischen den untersuchten drei Therapiemodalitäten nicht so gewaltig, als dass nicht andere, eher individuell geprägte Aspekte mit in die Therapieentscheidung einfließen sollten. Nachdem es sich bei dem Patienten mit Typ-2-Diabetes häufig um betagte und multimorbide Personen handelt, spielen die praktischen Modalitäten der Insulintherapie eine zunehmend wichtigere Rolle. Ob Studienergebnisse, die an Patienten mit einem Altersmedian von 62 Jahren erhoben wurden, auch auf die Patientengruppe der 75- bis 80-Jährigen zu übertragen ist, erscheint zweifelhaft. Gerade Untersuchungen der jüngsten Zeit lassen es auch sehr fraglich erscheinen, ob die "scharfen“ Einstellungskriterien der UKPTS und der 4T-Studie für betagtere Patienten wirklich das Nonplusultra darstellen.

H. S. FÜEßL =

- R. R. Holman et al.

Three-year efficacy of complex insulin regimens in type 2 diabetes. New Engl. J. Med. 361 (2009) 18, 1736-1747 